\title{
THE TEMPORAL DYNAMICS OF REGIONAL CITY SIZE DISTRIBUTION: ANDHRA PRADESH (1951-2001)
}

\author{
${ }^{1}$ G. Kumar and ${ }^{2}$ A. Subbarayan \\ ${ }^{1}$ Department of Statistics, S.R.M Arts and Science College, Kattankulathur-603 203, India \\ ${ }^{2}$ Department of Computer Applications, SRM University, Kattankulathur-603 203, India
}

Received 2014-03-06; Revised 2014-04-05; Accepted 2014-04-14

\begin{abstract}
Systems with measurable entities are characterized by certain properties of their size distribution. City Size Distribution (CSD) and the underlying city size dynamics have received attention in the urban economic literature in recent years. In this approach we aim at evaluating the temporal dynamics of city size distribution in Andhra Pradesh, an Indian state for the period 1951-2001. The research framework-which is based on a function relating population size to rank-is used to test for the trends of deconcentration cities of population over the study period. The expansion methodology is used to investigate the dynamics of rank size function in temporal dimension. We have studied the threshold size and its influence on temporal trends. The size distribution of cities/towns from one period to another is modeled by way of a Markov Chain. Our findings reveal that all places in the urban system are growing with small towns growing at a faster rate during study period. The largest cities and the smallest towns display higher persistence than the medium sized cities.
\end{abstract}

Keywords: City-Size Distribution, Pareto's Law, Zipf's Law, Rank-Size Distribution, Expansion Method, Temporal Models, Markov Chain

\section{INTRODUCTION}

The study of urban growth has proceeded in a number of different strands. One strand focuses on understanding the evolution of system of cities that is how cities of different size interact. Another strand focuses on physical structure of cities and how it may changes as cities grow. These strands are closely related. Among many theories advanced to explain city sizes, Zipf's law has been gaining continuous interests for its powerful description of city size distribution in many different countries and at different times within a country. The importance of this law is that, given very strong empirical support, it constitutes a minimum criterion of admissibility for any model of cities. This law has also received much attention regarding its theoretical justification of desirable situation and explanations of the process that govern city size distribution.

The study of the city size distribution is mainly conducted for entire countries, while such phenomenon is also studied in individual regions of a country, regardless of the type of defined regions. In this context Corresponding Author: G. Kumar, Department of Statistics, S.R.M Arts and Science College, Kattankulathur-603 203, India

it is important to have good empirical description of city size distribution on regional basis. The empirical facts indicate that the City growth process vary a great deal over time. The aim of this study is to study the temporal dynamics of city size distribution in Andhra Pradesh, an Indian state for the period 1951-2001.

In section 2 a detailed account of the urban scenario in Andhra Pradesh is presented. Section 3 deals with the theoretical aspects of city size distribution models and temporal models. The empirical findings in respect of temporal models are explained in section 4. In section 5, we estimate the first-order Markov chain and analyzed the intra-distribution of movements in the size distribution of cities. Conclusions based on the study are given in section 6 .

\section{URBAN SCENARIO IN ANDHRA PRADESH}

\subsection{Andhra Pradesh and its Demographic Profile}

Andhra Pradesh is one of the 29 states of India and covers an area of 2, 75, 000 square kilometers

21 JMSS 
$(106,204$ sq. miles). It is the fifth largest state in India both in area and population and ranks tenth in terms of its urban population. The density of the population is 275 per square kilometers. Andhra Pradesh is bounded on the north by Orissa and Chattisgarh, on the west Maharashtra and Karnataka, on the South by Tamil Nadu and in the east by Bay of Bengal with a coastal line of 974 kilometers. Andhra Pradesh is the third largest contributor to India's GDP. A demographic profile of Andhra Pradesh and India based on 2001 census is given in the following Table $\mathbf{1}$.

\subsection{Definition of Urban Area}

The definition of urban unit in the Census of India 2001 is as follows:

- All places with a municipal corporation, municipality, Cantonment board or notified town Area Committee

- All other places that satisfied the following criteria

- A minimum population of 5000

- At least $75 \%$ of the male working population should be engaged in non-agricultural pursuits and

- A density of population of at least 400 per sq. $\mathrm{km}$. (1000 per sq. mile)

All places, which have been notified under law and have local bodies like municipal corporations, municipalities, municipal committees, municipal boards, municipal town committees, cantonment boards, notified areas, notified area committees, town committees, town areas, town boards, town municipalities, sanitary boards, irrespective of their demographic characteristics have been included in the category of towns.

\subsection{Basic Statistics of Urban Population in Andhra Pradesh}

The following Table 2 contains the basic statistics of urban and rural population according to 2001 census.

The total number of urban dwellers in Andhra Pradesh as per the population total of the Census on India 2001 is 7, 62, 10, 007. Males number 3, 85, 27, 413 while females total $3,76,82,594$. The total number of urban dwellers in the country is 285,354 , 954 consisting of 150, 135, 894 males and 135, 219, 060 females. The percentage of urban population to total population in the country works out to $27.78 \%$ as against the ratio of $27.08 \%$ in Andhra Pradesh. Andhra Pradesh ranks fifth in term of it urban population 2001 .
Table1. Demographic profile of Andhra Pradesh and India (2001 Census)

\begin{tabular}{lcc}
\hline & $\begin{array}{l}\text { Andhra Pradesh } \\
\text { (millions) }\end{array}$ & $\begin{array}{l}\text { India } \\
\text { (millions) }\end{array}$ \\
\hline Total population & 76.21 & 1028.73 \\
Decadal population growth & 14.59 & 21.54 \\
Population density & 277.00 & 324.00 \\
Sex ratio & 978.00 & 933.00 \\
Literacy & 60.47 & 64.84 \\
Percentage of urban & 27.04 & 27.78 \\
to total population & & \\
\hline
\end{tabular}

Table 2. Population of Andhra Pradesh by sex and residence: 2001

\begin{tabular}{|c|c|c|c|c|}
\hline $\begin{array}{l}\text { Andhra } \\
\text { Pradesh }\end{array}$ & Male & Female & $\begin{array}{l}\text { Total } \\
\text { population }\end{array}$ & $\begin{array}{l}\text { Sex } \\
\text { ratio }\end{array}$ \\
\hline Urban & $1,05,90,209$ & $1,02,18,731$ & $2,08,08,940$ & 965 \\
\hline Rural & $2,79,37,204$ & $2,74,63,863$ & $5,54,01,067$ & 983 \\
\hline Total & $3,85,27,413$ & $3,76,82,594$ & $7,62,10,007$ & 978 \\
\hline
\end{tabular}

\section{CITY SIZE DISTRIBUTION MODELS}

\subsection{Rank Size Distribution}

The rank size function is most widely used to investigate the relationship between city size and rank. The estimation of rank size model requires the ordering of cities form the largest down to the smallest and it relates the rank of city with its size, measured by its population. Zipf (1949) used the rank size relationship to examine a wide variety of issues.

The simplest representation of this relationship is Equation 3.1.1:

$\mathrm{a}=\mathrm{pr}^{-\mathrm{b}}$

where, $\mathrm{a}$ is a constant, $\mathrm{p}$ is the population of a particular city and $r$ is its rank according to population size. When the exponent $b$ equals -1 , it is referred to Zipf as the rank size rule.

In a natural logarithmic form this relationship can also be expressed as Equation 3.1.2:

$\ln \mathrm{p}=\mathrm{a}+\mathrm{b} \ln \mathrm{r}$

where, a is the estimate of the intercept value, which is also the estimate of the natural logarithm of the population of the largest city and b is the estimate of the slope coefficient of the rank size curve.

The b-coefficient is the derivative of the logarithmic function. It evaluates the percentage rate 
of change in population size associated with the percentage rate of change in rank. On a doubly logarithmic paper, the rank size rule suggested by Zipf's appears as a straight line descending from left to right at an angle of 45 , indicating a slope of -1 .

\subsection{A Select Review of City Size Distribution Models and Temporal Model}

Auerbach (1913; Singer, 1936) studies were among the first to demonstrate a Pareto distribution of city sizes; that is, the Pareto's law describes the negative linear relationship between the logarithm of population size and the logarithm of city rank. Since the early $20^{\text {th }}$ century, numerous studies have been conducted on city rank-size distribution using Pareto's law (Allen, 1954; Malecki, 1975; 1980; Rosen and Resnick, 1980; Gabaix, 1999; Delgado and Godinho, 2004; Subbarayan, 2009; Subbarayan et al., 2011).

Nitsch (2005) used meta analysis to check the validity of Zipf's law as a distribution to city sizes and shown that the estimated Zipf coefficient was close to 1.1 agreeing that Rosen and Resnick (1980) and Soo (2005). Nitsch also enumerated some factors influencing the variation of slope coefficients, such as the base population (metropolitan areas), the country (USA, Japan and China) and the smaller number of observations.

Bengugui and Bhumenfeld-Liberthal (2009) proposed a dynamical growth model for cities and observed the changes in the value of the Pareto coefficient and justified the variation of the number of entities with time. Giesen and Suedekum (2011) have studied the salient rank size rule known as Zipf's law is not only satisfied for Germany's hierarchy, but also for the city size distribution in single German regions based on works of Gabaix (1999) and they observed that Zipf's law holds at both the regional and national level. Ye and Xie (2012) have examined temporal trajectories of key cities and the impacts of urban systems over space in China. The above facts have motivated the authors to study the temporal dynamics of a region viz., Andhra Pradesh in India.

\subsection{Changes in the City Size Distribution Over Time}

Changes in distributions of city sizes over time are generally treated rather casually in empirical research. Typically, rank size functions are fitted to distributions for a region at two or more points in time. The intercept and slope are noted to have changed and these are interpreted to indicate the relative rates of growth of large and small centres. A rigorous examination of intercept and slope changes over time would be able to indicate the extent to which a regional rank size distribution changed in several ways.

First, the intercept value 'a' can change because of a uniform rate of increase or decrease in the populations of all places in the urban system Fig. 1. In this case, all places are attracting migrants in proportion to their populations and are experiencing equal rates of natural growth (births and deaths).

In addition, the slope of the rank-size distribution, ' $b$ ' may change either because smaller urban areas are not growing at as rapid a rate as larger ones, forcing the tail of the distribution to the left as in Fig. 2. or because the populations of largest cities has increased to force the slope of the distribution to steeper to meet the increased intercept Fig. 3.

\subsection{Temporal Models}

To separate the influences of the above phenomena, we apply Casetti (1972) expansion method. The expansion method introduces a procedure through which a 'terminal model' is generated from an 'initial model' by making the parameters of the latter functions of other relevant variables. An expansion in a specific dimension, such as time or distance, would then capture the quantitative change of initial parameters along that dimension. To investigate changes in an urban system through time, equation is defined as the initial model. Both the parameter a, which is the estimate of the natural logarithm of the largest city's population and the slope coefficient $b$ can vary through time and they can be redefined by the following 'expansion Equation 3.4.1 and 3.4.2:

$$
\begin{aligned}
& a=a_{0}+a_{1} t \\
& b=b_{0}+b_{1} t
\end{aligned}
$$

where, $\mathrm{t}$ is time. By replacing the parameters in equation by the right-hand sides of equations and the following terminal model is obtained Equation 3.4.3:

$\ln p=a_{0}+a_{1} t+b_{0} \ln r+b_{1} t \ln r$

In the logarithmic form above, $a_{0}+a_{1} t$ and $b_{0}+b_{1} t$ are linear expansion of $a$ and $b$ as functions of time. The significance of the coefficient of $t$ and $t \ln r$ is tested as follows: 


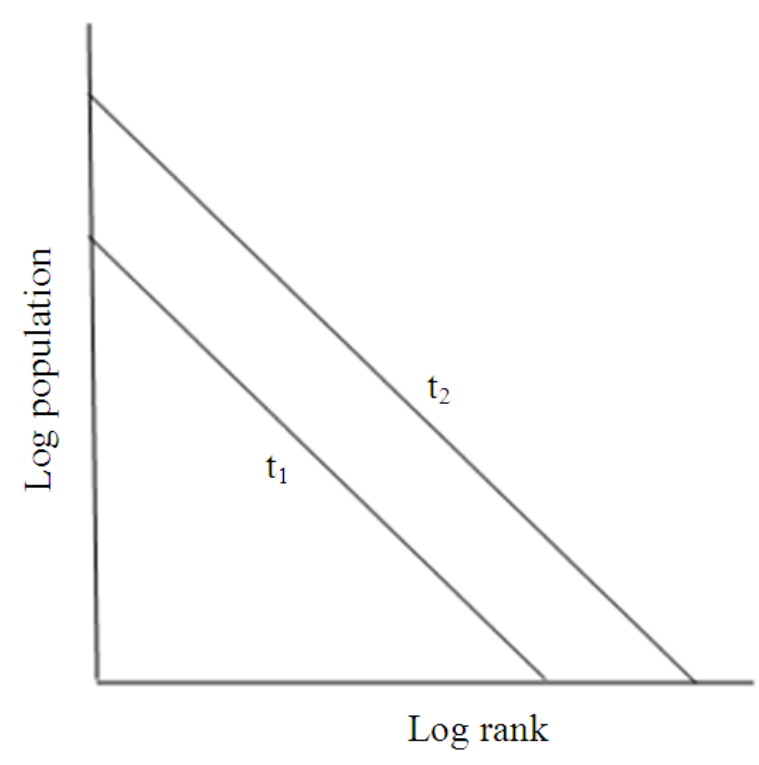

Fig. 1. Increase in intercept value from $t_{1}$ to $t_{2}$ owing to uniform growth of cities/towns

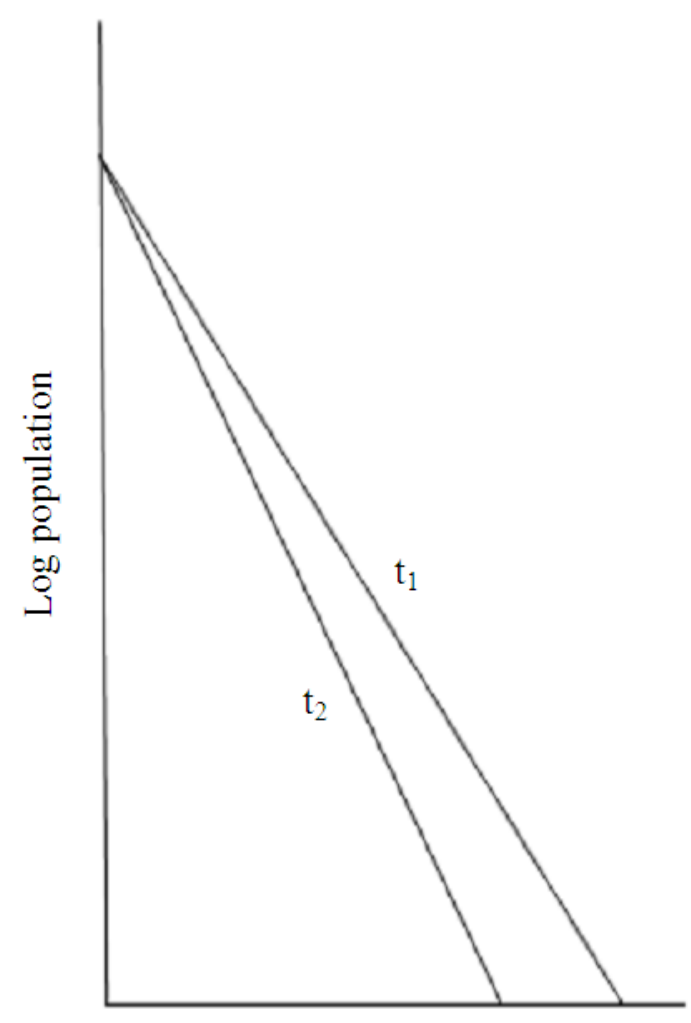

Log rank

Fig. 2. Increased slope in $\mathrm{t}_{2}$ owing to decline to smaller towns Science Publications

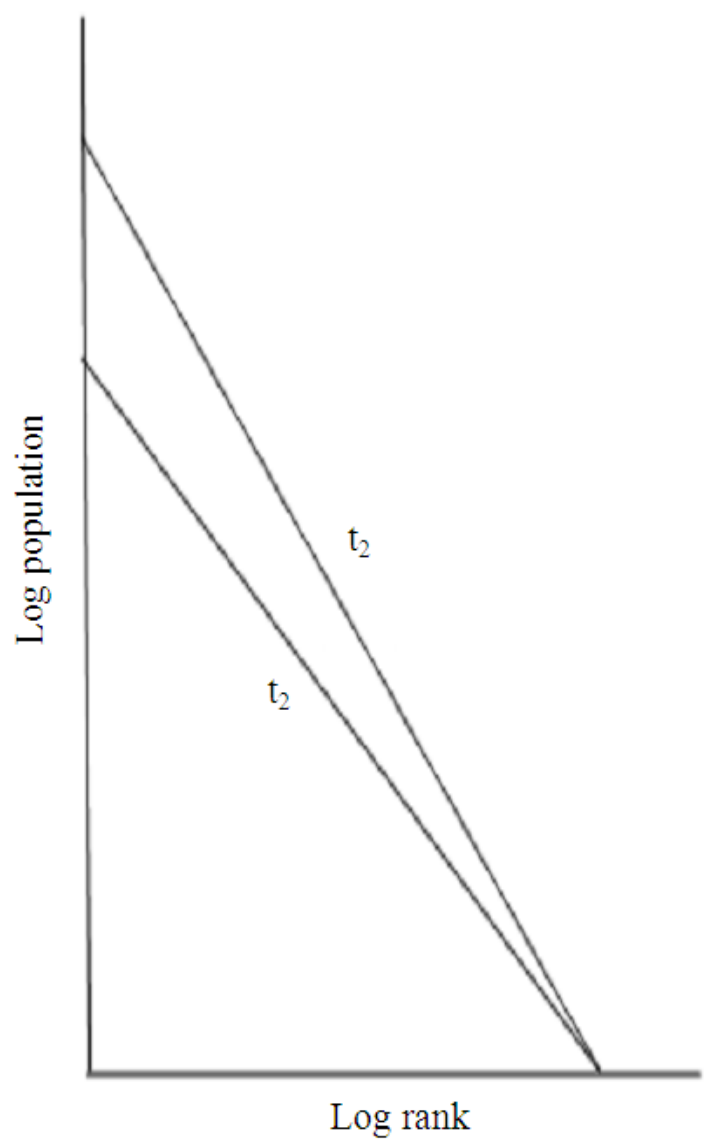

Fig. 3. Increased slope in $t_{2}$ owing to growth of larger centers

- If $\mathrm{a}_{1}$ is significantly different from zero, but $\mathrm{b}_{1}$ is not significant, then all the centers in the system have grown at the same rate and the change in the population is statistically significant

- If $a_{1}$ is not significant but $b_{1}$ is significant and positive, then the change in the slope is showing to an absolute decline in smaller settlements in the region

- If both $a_{1}$ and $b_{1}$ are significant and positive, then the larger places are shown to have grown relatively faster than the small centres

- If $a_{1}$ is significantly positive and $b_{1}$ is significantly negative, then all places in the urban system are growing, with smaller places growing at a faster rate

\section{DATA AND METHODS}

\subsection{Urban Size Class Under Indian Census}

India has very rich source of information for urban studies. The census volumes, both at the National and 
state and district levels, provide a mine of information for rural and urban places for period of 100 years. It is also main source of information for temporal studies focusing in the recent past. The census periods covered are: 1951, 1961, 1971, 1981, 1991 and 2001.

Urban Population by size classification is based on the following:

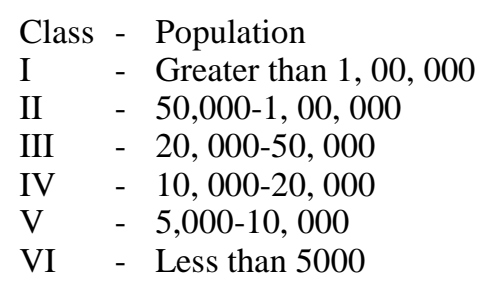

The number of cities/towns for each census year under six classes for Andhra Pradesh is given in the following Table 3.

Figure 4 Illustrates the change in Andhra Pradesh rank size distribution for the period 1951-2001.

\subsection{Analysis of the Results/Empirical findings}

As a basis for comparison with conventional methods of measuring change in rank-size systems, the standard logarithmic rank-size function was initially fitted to the data for each census year, employing a natural logarithmic transformation. The result is shown in Table 4 with Standard Error beneath each regression coefficient.

The regression result for the successive years clearly shows an increasing intercept, from 12.835 in 1951 to 15.623 in 2001 . In addition, the slope of the rank size distribution increases from 0.781 in 1951 to 1.126 in 2001 and it has become steeper over time. The estimates of the Pareto Exponent is given in the following Fig. 5.

To determine the sources of changes in the urban system, the expanded logarithmic rank size model (3.4.3) was fitted for the period 1951-2001. The results are shown in Table 5.

Since $a_{1}$ is significantly positive and $b_{1}$ is significantly negative, then all places in the urban system are growing, with smaller places growing at a faster rate over the 60 years period.

\subsection{Threshold Size and Its Influence on Temporal Trends}

Studies that explore the relationship between slope and threshold often test only for a few threshold points. Guerin-Pace (1995) examined the rank size parameters sensitivity using French city system, with a data which has six threshold points.

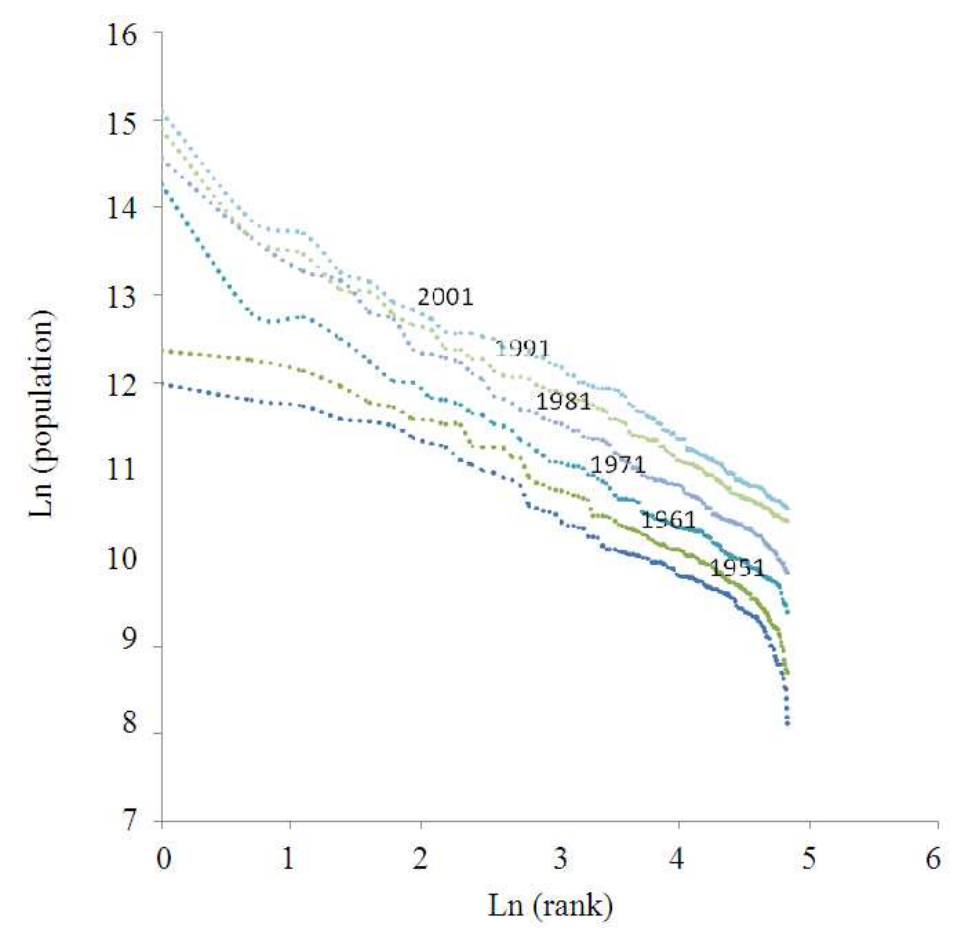

Fig. 4. Rank-size distribution of Andhra Pradesh Cities/Towns 1951-2001 


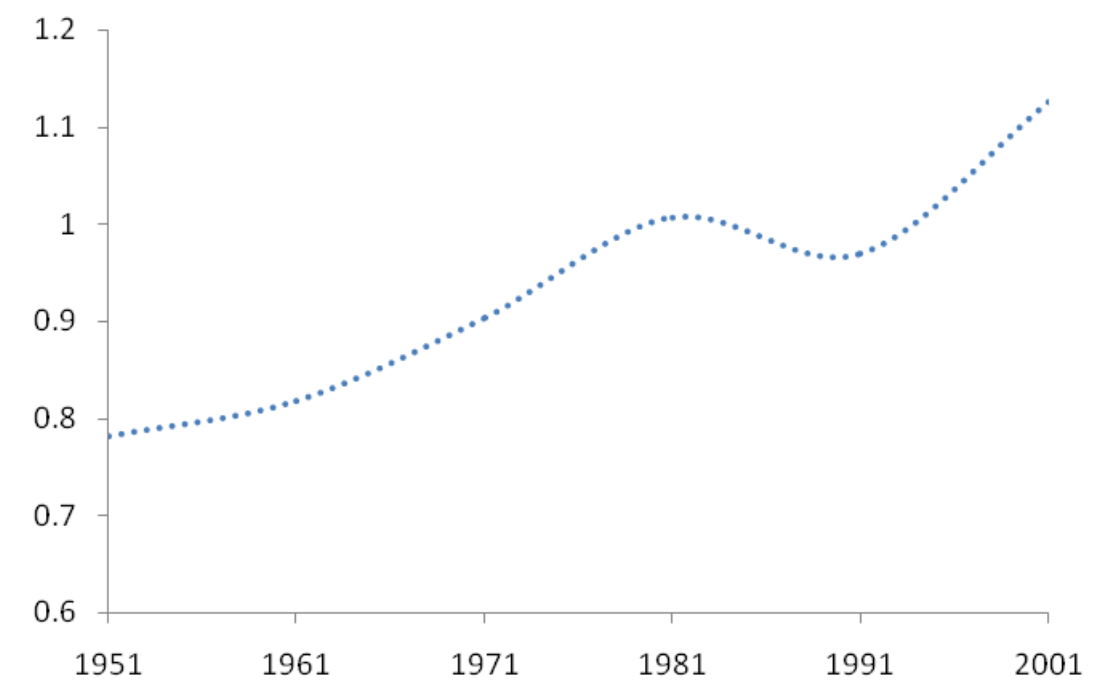

Fig. 5. Evolution of the estimates of the Pareto Exponent (b-coefficient)

Table 3. Andhra Pradesh: City size distribution (No. of cities/towns)

\begin{tabular}{|c|c|c|c|c|c|c|c|}
\hline & $>1,00,000$ & $\begin{array}{l}50,000- \\
1,00,000\end{array}$ & $\begin{array}{l}20,000- \\
50,000\end{array}$ & $\begin{array}{l}10,000- \\
20,000\end{array}$ & $\begin{array}{l}5,000- \\
10,000\end{array}$ & $<5,000$ & Total \\
\hline 1951 & 5 & 11 & 34 & 54 & 19 & 3 & 126 \\
\hline 1961 & 10 & 9 & 50 & 45 & 14 & 0 & 128 \\
\hline 1971 & 13 & 18 & 63 & 37 & 10 & 1 & 142 \\
\hline 1981 & 22 & 33 & 67 & 24 & 10 & 1 & 157 \\
\hline 1991 & 36 & 42 & 68 & 22 & 6 & 0 & 174 \\
\hline 2001 & 47 & 52 & 56 & 33 & 21 & 2 & 211 \\
\hline
\end{tabular}

Table 4. Estimates for rank-size function

\begin{tabular}{lllll}
\hline Year & $\mathrm{a}$ & $\mathrm{b}$ & $\mathrm{R}^{2}$ & Sig. level \\
\hline 1951 & $12.835(0.082)$ & $0.781(0.021)$ & 0.921 & 0.0001 \\
1961 & $13.232(0.073)$ & $0.818(0.018)$ & 0.941 & 0.0001 \\
1971 & $13.899(0.069)$ & $0.904(0.017)$ & 0.953 & 0.0001 \\
1981 & $14.659(0.092)$ & $1.007(0.022)$ & 0.932 & 0.0001 \\
1991 & $14.861(0.101)$ & $0.969(0.024)$ & 0.908 & 0.0001 \\
2001 & $15.623(0.135)$ & $1.126(0.03)$ & 0.870 & 0.0001 \\
\hline
\end{tabular}

Table 5. Estimates for rank-size function expanded in time

\begin{tabular}{llll}
\hline Parameter & Estimates & Standard error & Sig. level \\
\hline $\mathrm{a}_{0}$ & 15.461 & 0.215 & 0.0001 \\
$\mathrm{a}_{1}$ & 7.288 & 0.222 & 0.0001 \\
$\mathrm{~b}_{0}$ & -1.519 & 0.052 & 0.0001 \\
$\mathrm{~b}_{1}$ & -0.928 & 0.03 & 0.0001 \\
\hline $\mathrm{R}^{2}=0.606, \mathrm{~F}=$ 478.810, Sig.level $=0.0001, \mathrm{DF}=3,934$
\end{tabular}

$\mathrm{Xu}$ and Zhu (2009) tested the top 100, 200, 300 and 400 Chinese cities in different years and the slope increase when the sample size moves towards the top of the city size hierarchy. Eeckhout $(2004 ; 2009)$ has also found that the Pareto Distribution resemble, at best, the upper tail of the rank-size distribution. Soo
(2007) analyzed the rank size distribution of Malaysian cities and examined the change in Pareto coefficient by successively reducing the number of cities in sampling by using the number threshold method. Li and Sui (2012) have shown that slope is sensitive to sample size and the truncation point and concluded that the percentage threshold method involved those gives consistent results early for China's urban system.

In this study we have considered 6 threshold points and studied the influence of truncation on temporal trends. The results are presented in Table 6.

The intercept tends to increase steadily over time for each threshold size reflecting the increasing size of the largest cities. The slope also increases over time with threshold population of 50000 and above.

The following Table 7 shows the results of the estimated parameters $a_{0}, a_{1}, b_{0}$ and $b_{1}$ employing the procedure outlined in section 3.4 with respect to threshold populations viz., 5000, 10,000, 25,000, 50,000, $75,000,1,00,00$ and above for the period 1951-2001. 
Table 6. Comparison of rank-size parameter estimates for six time periods

\begin{tabular}{llllllll}
\hline $\begin{array}{l}\text { Threshold } \\
\text { population }\end{array}$ & & 1951 & 1961 & 1971 & 1981 & 1991 & 2001 \\
\hline 5000 & $\mathrm{a}$ & 12.768 & 13.232 & 13.877 & 14.634 & 14.861 & 15.572 \\
& $\mathrm{~b}$ & $0.759(0.017)$ & $0.818(0.018)$ & $0.897(0.016)$ & $0.999(0.021)$ & $0.969(0.024)$ & $1.111(0.029)$ \\
& $\mathrm{R}$ & 0.946 & 0.941 & 0.96 & 0.938 & 0.908 & 0.88 \\
& $\mathrm{n}$ & 123 & 128 & 141 & 156 & 174 & 209 \\
10000 & $\mathrm{a}$ & 12.58 & 13.059 & 13.75 & 14.474 & 14.729 & 15.201 \\
& $\mathrm{~b}$ & $0.694(0.01)$ & $0.759(0.011)$ & $0.855(0.01)$ & $0.948(0.015)$ & $0.928(0.018)$ & $1.002(0.02)$ \\
& $\mathrm{R}$ & 0.978 & 0.976 & 0.983 & 0.967 & 0.942 & 0.93 \\
& $\mathrm{n}$ & 104 & 114 & 131 & 167 & 188 \\
25000 & $\mathrm{a}$ & 12.406 & 12.862 & 13.662 & 145.226 & 14.475 & 14.772 \\
& $\mathrm{~b}$ & $0.613(0.032)$ & $0.684(0.018)$ & $0.826(0.012)$ & $0.866(0.006)$ & $0.848(0.01)$ & $0.869(0.01)$ \\
& $\mathrm{R}$ & 0.927 & 0.967 & 0.985 & 0.995 & 0.982 & 0.982 \\
& $\mathrm{n}$ & 30 & 49 & 74 & 108 & 146 & 148 \\
50000 & $\mathrm{a}$ & 12.157 & 12.625 & 13.728 & 14.263 & 14.327 & 14.632 \\
& $\mathrm{~b}$ & $0.443(0.03)$ & $0.545(0.035)$ & $0.854(0.029)$ & $0.881(0.012)$ & $0.798(0.011)$ & $0.823(0.011)$ \\
& $\mathrm{R}$ & 0.939 & 0.936 & 0.968 & 0.991 & 0.986 & 0.983 \\
75000 & $\mathrm{n}$ & 16 & 19 & 31 & 78 & 99 \\
& $\mathrm{a}$ & 12.037 & 12.535 & 13.802 & 14.313 & 14.318 & 14.53 \\
& $\mathrm{~b}$ & $0.327(0.025)$ & $0.476(0.031)$ & $0.901(0.051)$ & $0.905(0.019)$ & $0.794(0.018)$ & $0.782(0.016)$ \\
& $\mathrm{R}$ & 0.96 & 0.952 & 0.951 & 0.987 & 0.976 & 0.975 \\
100000 & $\mathrm{n}$ & 9 & 14 & 18 & 32 & 69 & 1 \\
& $\mathrm{a}$ & 11.994 & 12.48 & 13.852 & 14.407 & 14.337 & 14.484 \\
& $\mathrm{~b}$ & $0.269(0.023)$ & $0.422(0.034)$ & $0.943(0.073)$ & $0.962(0.02)$ & $0.803(0.025)$ & $0.762(0.021)$ \\
& $\mathrm{R} 2$ & 0.978 & 0.951 & 0.938 & 0.991 & 0.967 & 0.968 \\
& $\mathrm{n}$ & 5 & 10 & 13 & 22 & 36 & 47 \\
\hline
\end{tabular}

Table 7. Estimated parameters of the expanded rank-size model

\begin{tabular}{llllll}
\hline Threshold population & $\mathrm{a}_{0}$ & $\mathrm{a}_{1}$ & $\mathrm{~b}_{0}$ & $\mathrm{~b}_{1}$ & $\mathrm{R}^{2}$ \\
\hline 5000 & 12.724 & $0.574(0.023)$ & $0.751(0.019)$ & $0.069(0.006)$ & 0.922 \\
10000 & 12.623 & $0.536(0.017)$ & $0.713(0.014)$ & $0.060(0.004)$ & 0.957 \\
25000 & 12.539 & $0.473(0.011)$ & $0.674(0.012)$ & $0.043(0.003)$ & 0.979 \\
50000 & 12.452 & $0.472(0.014)$ & $0.607(0.020)$ & $0.051(0.005)$ & 0.970 \\
75000 & 12.410 & $0.475(0.020)$ & $0.573(0.033)$ & $0.056(0.008)$ & 0.952 \\
100000 & 12.400 & $0.479(0.025)$ & $0.573(0.048)$ & $0.057(0.012)$ & 0.935 \\
\hline
\end{tabular}

The following results are observed:

- The values of $a_{0}$ and $b_{0}$ decreasing over the threshold populations

- The value of $a_{1}$ shows a decreasing pattern upto the threshold population 50,000 and then increases

- The value of $b_{1}$, shows a decreasing pattern upto the threshold population 25,000 and then increases

\section{MOVEMENTS WITHIN THE DISTRIBUTION}

\subsection{Intra-Distribution Movements In The Size Distribution Of Cities}

The approach described in the above sections corresponds to a static point of view that does not permit any analysis of movements from one period to another Intra-distribution of movements in the size distribution of cities from one period to another can be modeled by way of a Markov Chain. The dynamic approach is able to explicitly capture the movements of cities/towns between periods. This approach will help us to predict the future size distribution of the cities/towns and to describe the behavior of the whole system. In this study we have considered the method proposed by Quah (1993) and used in empirical studies on the convergence in growth rates between countries or regions.

This method has been applied to the city size distribution of various countries by (Eaton and Eckstein, 1997; Black and Henderson, 1999; Lanaspa et al., 2003; Anderson and Ge, 2005; Gallo and Yrigoyen, 2008; $\mathrm{Xu}$ and Zhu, 2009). 


\subsection{Methdology}

A Markov chain, which we will denote by $\left\{X_{t}\right\}$ is a stochastic process with a parametrical space $\mathrm{T}$ of discrete time and a finite space of states $E$ that verifies the following so called Markov property Equation 5.1.1:

$$
\begin{aligned}
& P\left[X_{t}=j \mid X_{t-1}=i, X_{t-2}=c, \ldots X_{1}=a\right] \\
& =p\left[X_{t}=j \mid X_{t-1}=i\right]=p_{i j}(t)
\end{aligned}
$$

where, $\mathrm{j}, \mathrm{i}, \mathrm{c}, \mathrm{a} \in \mathrm{E}$. This condition implies that the future of the process depends on its present and not on its history.

The transition probabilities $\mathrm{p}_{\mathrm{ij}}(\mathrm{t})$ capture the probability that the state $i$ in $t-1$ is followed by state $\mathrm{j}$ in $\mathrm{t}$. It is assumed that the Markov chain is stationary, that is to say, that it verifies:

$$
\mathrm{p}_{\mathrm{ij}}(\mathrm{t})=\mathrm{p}_{\mathrm{ij}} .
$$

We can group all the possible transition probabilities in a stochastic matrix $\mathrm{P}$, called the transition matrix Equation 5.1.2:

$$
\mathrm{P}=\left(\mathrm{p}_{\mathrm{ij}}\right)=\left[\begin{array}{cccc}
\mathrm{p}_{11} & \mathrm{p}_{12} & \ldots & \mathrm{p}_{1 \mathrm{M}} \\
\mathrm{p}_{21} & \mathrm{p}_{22} \ldots & \mathrm{p}_{2 \mathrm{M}} \\
\cdot & \cdot & \cdot \\
\cdot & \cdot & \cdot \\
\cdot & \cdot & \cdot \\
\cdot & \cdot & \cdot \\
\mathrm{p}_{\mathrm{M} 1} & \mathrm{p} & \ldots & \mathrm{p}_{\mathrm{NM}}
\end{array}\right]
$$

where, $\mathrm{p}_{\mathrm{ij}} \geq 0, \mathrm{i}, \mathrm{j} \in \mathrm{E}$ and $\Sigma \mathrm{p}_{\mathrm{ij}}=1, \forall \mathrm{i} \varepsilon \in$.

This matrix $\mathrm{P}$ completely characterizes the intradistribution dynamics, thereby defining the movement from one period to another.

In our empirical application we estimate $\hat{\mathrm{p}}_{\mathrm{ij}}$. If the matrix $\mathrm{P}$ is invariant over time and its element can be estimated from the observed frequencies in the changes of state from one period to another. Hamilton (1994) has shown that, the maximum likelihood estimator of $\mathrm{p}_{\mathrm{ij}}$ is Equation 5.1.3:

$$
\hat{\mathrm{p}}_{\mathrm{ij}}=\frac{\mathrm{n}_{\mathrm{ij}}}{\sum_{\mathrm{j} \in \mathrm{s}} \mathrm{n}_{\mathrm{ij}}}
$$

where, $n_{i j}$ is the observed number of cities that, having been initially in state $\mathrm{i}$, appear in state $\mathrm{j}$ in the immediately following period.
Hamilton (1994) demonstrated that under certain conditions Equaion 5.1.4:

$\underset{\mathrm{Q} \rightarrow \infty}{\mathrm{Lt}} \mathrm{P}^{\mathrm{Q}}$

Exists and is equal to $\pi 1$, where $\pi$ is a Mx 1 vector and 1 is a $1 \mathrm{xM}$ row vector of ones. The vector $\pi$ which, if its exists, is unique, is given the name steady state distribution or, more usually, the vector of ergodic probabilities. This vector $\pi$ offers very interesting information, given that it describes the future distribution of the cities if the movements observed in the period are repeated to infinity.

\subsection{Results based on Transition Probability Matrix}

The use of Markov Chain requires making the space of states discrete, in order to manage a finite number of categories. Following Eaton and Eckstein (1997) we have defined six states which are related with the average population for each Census period. These states are as follows:

Cities/towns whose population is below $30 \%$ of the average population:

- $\quad$ Between 30 and $50 \%$ of the average

- Between 50 and $75 \%$ of the average

- Between 75 and $100 \%$

- Between the average and twice the average and finally more than twice the average

The average has been obtained from the 125 cities/towns in each period. It is important to note that the Andhra Pradesh urban hierarchy has experienced significant changes during 1951-2001, even to the extent of some cities/towns losing population over the years and others growing at very high rates.

The following Table 8 contains the first order transition probably matrix between 1951-2001 with Maximum likelihood estimates $\hat{\mathrm{p}}_{\mathrm{ij}}$ of the transition probabilities for population.

We can draw the following conclusions based on the values in the transition probability matrix:

- First, the persistence, which is given by the values in the diagonal, is greater for the Class I and Class II cities/towns

- $\quad$ The medium sized cities/towns [Class III, IV and V] have more probability to move to the next higher large cities

- In respect of Class II cities/towns, the probability of moving to Class I cities is very low 
Table 8. Transition matrix for Andhra Pradesh (1951-2001)

\begin{tabular}{lllllll}
\hline & $\infty$ & 2 & 1 & 0.75 & 0.50 & 0.3 \\
$($ Class I) & (Class II) & (Class III) & 0.0000 & $\begin{array}{l}\text { (Class V) } \\
(\text { Class VI) }\end{array}$ \\
\hline$\infty$ & 0.6000 & 0.4000 & 0.0000 & 0.0000 & 0.0000 \\
2 & 0.0710 & 0.7150 & 0.1430 & 0.000 & 0.0710 & 0.0000 \\
1 & 0.0430 & 0.1740 & 0.1740 & 0.2610 & 0.3480 & 0.0000 \\
0.75 & 0.0000 & 0.0000 & 0.1870 & 0.3130 & 0.4060 & 0.0940 \\
0.50 & 0.0000 & 0.0340 & 0.1030 & 0.2070 & 0.4840 & 0.1720 \\
0.3 & 0.0830 & 0.0000 & 0.0000 & 0.0000 & 0.2500 & 0.6670 \\
Ergodic & 0.0580 & 0.1890 & 0.1120 & 0.1360 & 0.3060 & 0.1980 \\
\hline
\end{tabular}

\section{CONCLUSION}

The long run analysis of the size distribution of cities in a region offers information about what has occurred and it allow us to glimpse what might be the future behavior. In this study we have carried out such an analysis for a region/state in India for the period 1951-2001.

The conclusions emerge from the empirical analysis are:

- Throughout the study period all cities/towns in the state are growing with smaller places growing at a faster rate

- The intercept tends to increase steadily over time for each threshold reflecting the increasing size of the largest cities. The slope also increases over time with threshold population 50,000 and above

The Markov chain analysis shows a low inter class mobility, i.e., high persistence of largest cities/towns and smallest cities/towns to stay in their class from one decade to another over the period of study. Thus the largest cities/towns and smallest cities/towns display higher persistence than the medium sized cities, which have more probability of moving to next higher larger cities/towns and smaller cities/towns. This proves the major role played by medium-sized cities in the process of urban agglomeration occurred in Andhra Pradesh during 1951-2001. In general terms, movements up are slower than movements down, especially among larger cities.

\section{REFERENCES}

Allen, G.R.P., 1954. The curbe des population: A further analysis. Bulletin of the Oxford University Institute of Statistics.

Anderson, G. and Y. Ge, 2005. The size distribution of Chinese cities. Reg. Sci. Urban Eco., 35: 756-766. DOI: 10.1016/j.regsciurbeco.2005.01.003
Auerbach, F., 1913. Das gesetz der bevölkerungskonzentration. Petermanns Geographische Mitteilungen, 59: 74-76.

Bengugui, L. and E. Bhumenfeld-Liberthal, 2009. The temporal evolution of the city size distribution. Phys. A, 388: 1187-1195. DOI: 10.1016/j.physa.2008.12.009

Black, D. and V. Henderson, 1999. Spatial evolution of population and industry in the united states. Am. Econ. Rev., 89: 321-327. DOI: 10.1257/aer.89.2.321

Casetti, E., 1972. Generating models by the expansion method: Applications to geographical research. Geographical Anal., 4: 81-91. DOI: 10.1111/j.15384632.1972.tb00458.x

Delgado, A.P. and I.M. Godinho, 2004. The evolution of city size distribution in Portugal: 1864-2001. Faculdade De Economia, Universidade Do Porto.

Eaton, J. and Z. Eckstein, 1997. City and growth: Theory and evidence from France and Japan. Reg. Sci. Urban Econ., 27: 443-474. DOI: 10.1016/S01660462(97)80005-1

Eeckhout, J., 2004. Gibrat's law for (All) cities. Am. Econ. Rev., 94: 1429-1451. DOI: $10.1257 / 0002828043052303$

Eeckhout, J., 2009. Gibrat's law for (all) cities: Reply. Am. Econ. Rev., 99: 1676-1683.

Gabaix, X., 1999. Zipf's law and the growth of cities. Am. Econ. Rev., 89: 129-132.

Gallo, J.E. and C. Chasco, 2008. Spatial analysis of urban growth in Spain 1900-2001. Empirical Econ., 34: 59-80. DOI: 10.1007/s00181-007-0150-5

Guerin-Pace, F., 1995. Rank size distribution and the process of urban growth. Urban Stud., 32: 551-562. DOI: $10.1080 / 00420989550012960$

Giesen, K. and J. Suedekum, 2011. Zipf's law for cities in the regions and the country. J. Econ. Geog., 11: 667-686. DOI: 10.1093/jeg/lbq019

Hamilton, J.D., 1994. Time Series Analysis. 1 st Edn., Princeton University Press, Princeton, ISBN-10: 0691042896, pp: 799. 
Lanaspa, L., F. Pueyo and F. Sanz, 2003. Evolution of the spanish urban structure during twentieth century. Urban Stud., 40: 567-580. DOI: 10.1080/0042098032000053923

Li, S. and D. Sui, 2012, Pareto's law and sample size: A case study of China's urban system 1984-2008. Geo J., 78: 615-626. DOI: 10.1007/s10708-012-9455-9

Malecki, E.J., 1975. Examining change in rank size system of cities. Professional Geographers, 27: 4347. DOI: 10.1111/j.0033-0124.1975.00043.x

Malecki, E.J., 1980. Growth and change in the analysis of rank-size distribution: Empirical findings. Environ. Plann. A, 12: 41-52. DOI: 10.1068/a120041

Nitsch, V., 2005. Zipf zipped. J. Urban Econ., 57: 86100. DOI: $10.1016 /$ j.jue.2004.09.002

Quah, D.T., 1993. Empirical cross-section dynamics in economic growth. Eur. Econ. Rev., 37: 426-434. DOI: 10.1016/0014-2921(93)90031-5

Rosen, K.T. and M. Resnick, 1980. The size Distribution Cities: An examination of the Pareto law and primacy. J. Urban Econ., 8: 165-186. DOI: 10.1016/0094-1190(80)90043-1

Singer, H.W., 1936. The courbe des population: A parallel to pareto's law. Econ. J., 46: 254-263.
Soo, K.T., 2005. Zipf's law for Cities: A cross country investigation. Reg. Sci. Urban Econ., 35: 239-263. DOI: 10.1016/j.regsciurbeco.2004.04.004

Soo, K.T., 2007. Zipf's law and urban growth in Malaysia. Urban Stu., 44: 1-14. DOI: 10.1080/00420980601023869

Subbarayan, A., 2009. The size distribution of cities in Tamilnadu (1901-2001). Int. J. Agric. Statis. Sci., 5: 373-382.

Subbarayan, A., Kumar, G. Christopher and V. Amalraj, 2011. The temporal and spatial dynamics of regional city-size distribution: Tamilnadu (1951-2001). Int. J. Agric. Stat. Sci., 7: 535-554.

$\mathrm{Xu}, \mathrm{Z}$. and Zhu, N. 2009. City size distribution in China: Are large cities dominant? Urban Stud., 46: 21592185. DOI: $10.1177 / 0042098009339432$

Ye, X. and Y. Xie, 2012. Re-examination of Zipf's law and urban dynamic in China: A regional approach. Ann. Reg. Sci., 49: 135-156. DOI: 10.1007/s00168011-0442-8

Zipf, G.K., 1949. Human Behavior and the Principle of Least Effort: An Introduction to Human Ecology. 1 st Edn., Addison-Wesley Press, Cambridge, pp: 573. 